\title{
Integration of the New Trading Support System with the Existing IT System at One SEE Generation Company
}

\author{
Suzana Cvetićanin ${ }^{1}$, Goran Jakupović ${ }^{1}$, Ninel Čukalevski ${ }^{1}{ }^{1}$ Radomir Stamatović ${ }^{1}$, Davor Pupovac ${ }^{2}$
}

\section{Abstract}

The PE EPS (Electric Power Industry of Serbia) is in the process of procurement of the new, state-of-the-art, trading support system of the ETRM (Enterprise Trading and Risk Management) type that will considerably improve current energy/ancillary services trading practices of EPS at the SEE energy/service market.

To speed up the implementation process and to enable ETRM proper use it was necessary to migrate some of the data from the existing trading contracts database. Also, necessary data about hourly planned unit generations, interchange and other related data have to be "captured" on-line from the existing web-based IT system.

This paper will briefly describe the generation company (Gen Co) current IT support and will present solution architecture one that enabled data migration into the new ETRM system. It will also explain proposed procedure for the acquisition, extraction and transfer of the on-line/archive TSO and GenCo data from the existing web-based system to the new trading support system at the trading floor of one SEE Gen Co.

At the end paper will present information about the information technologies used for the solution implementation, as well as experience from its initial practical use.

\footnotetext{
${ }^{1}$ Institute Mihajlo Pupin

15 Volgina, Belgrade, Serbia

(e-mail: suzana.cveticanin@ pupin.rs, goran.jakupovic@pupin.rs, ninel.cukalevski@pupin.rs, rade.stamatovic@pupin.rs )

${ }^{2}$ PE EPS

Department for Electricity Trading

412 Vojvode Stepe, Belgrade, Serbia

(e-mail: davor.pupovac@eps.rs )
}

\author{
Keywords \\ Trading support system, ETRM, data migration, \\ integration
}

\section{Introduction}

The electricity market was initially introduced into the Serbian electricity sector by adoption of the Energy Law with a view to enhancing the efficiency of the sector through application of market mechanism forces to the electricity production and supply area, maintaining, however, the economic regulation of electricity transmission and distribution activities as natural monopolies.

In the first phase, starting from the day when the Energy Law became effective in 2004, the electricity market was potentially open for all customers with an annual electricity consumption of greater than $25 \mathrm{GWh}$.

Gradual opening of the Serbian electricity market is finished and since January 1, 2015 fully open (when market was opened for households in line with the ratification of the Energy Community Treaty).

Electric Power Industry of Serbia (PE EPS) operates power stations with total installed capacity of $8359 \mathrm{MW}$ and it is the largest brown coal producer in Serbia. By means of distribution networks, the company provides over 3.5 million customers with electricity throughout the entire Republic of Serbia. In 2005 previously vertically integrated Serbian power utility was split into two independent public enterprises PE “ Electric Power Industry of Serbia“ - generation and distribution company and PE "Elektromreža Srbije" - Serbian Transmission System and Market Operator, thus creating

This is an Open Access article distributed in accordance with the Creative Commons Attribution Non Commercial (CC-BY-NC-ND 4.0) license, which permits others to copy or share the article, provided original work is properly cited and that this is not done for commercial purposes. Users may not remix, transform, or build upon the material and may not distribute the modified material (http://creativecommons.org/licenses/by-nc/4.0/) 
conditions for development of electricity market. During transitional period in electricity market development Institute Mihajlo Pupin developed trading contacts database as well as DB for other necessary data about planned unit generations, interchange, etc. In 2014 PE EPS started implementation of the new trading support system, of the ETRM (Enterprise Trading and Risk Management) type developed by IPESOFT in cooperation with ATOS and Institute Mihajlo Pupin.

First phase of the project, fully functional "Front Office" which offers support for electricity trading as well as cross border capacity and $\mathrm{CO} 2$ trading was finished in January 2015. In order to speed up the implementation process it was necessary to perform data issuing of invoices in Serbian and English. It also provides an overview/correction of data entered.

Contracts_EPS database contains data about all contracts since 2010 (among other there are around 7000 commercial contracts) such as: start date of contract, end date, price, duration (day, month, year, quarter ...), counterparties and addresses, types of contracts (sale/purchase), exchange rates etc. Almost all data is entered manually. It is MySQL 5.0.26 database.

WEB Diary application is database driven PHP (4.3.9.) application as well, which is predominantly used for data overview, but it allows data entry and data corrections.

db_diary_EPS database contains data about

\section{TSO EMS}

Power Plants of EPS

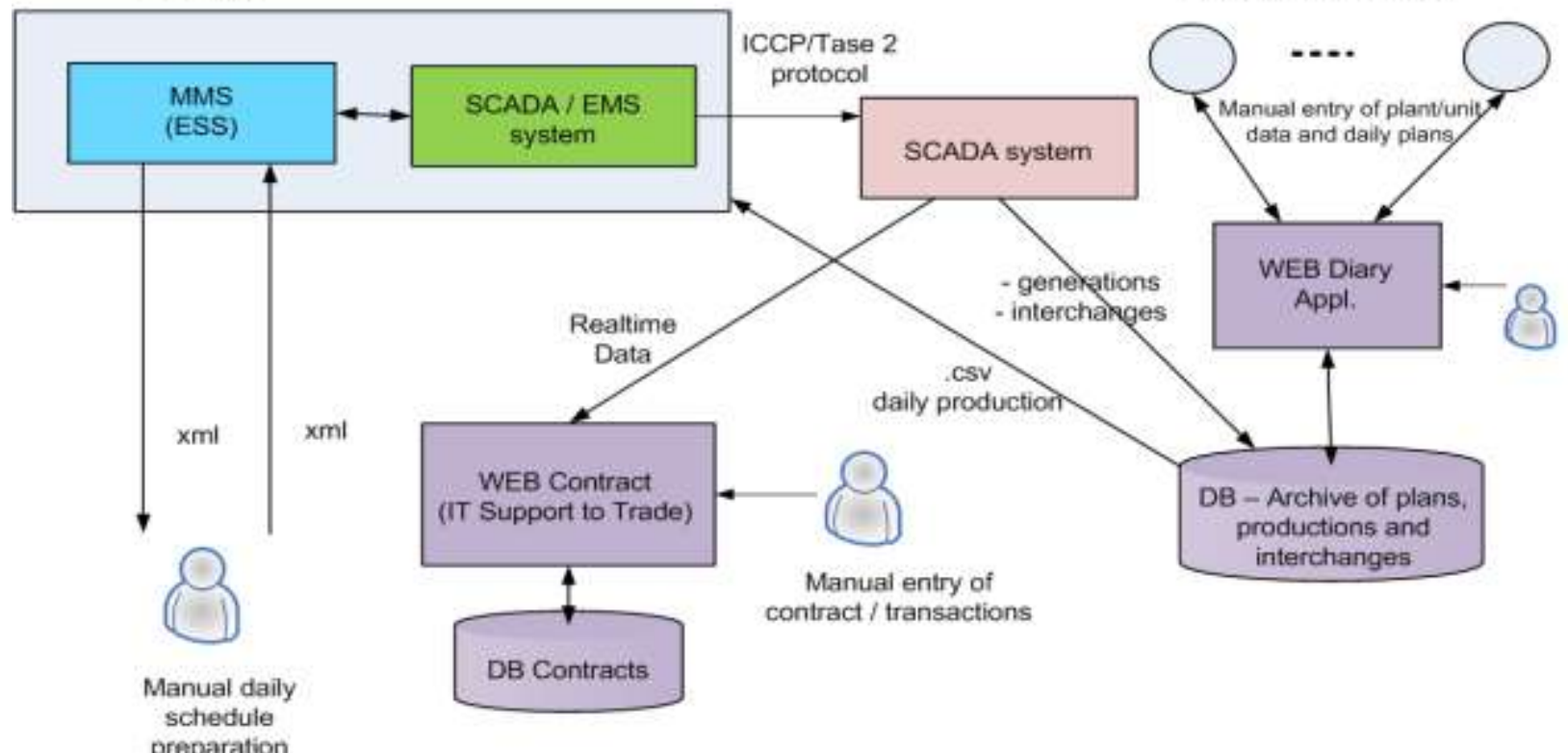

Figure 1 Architecture of the old system

migration from existing trading contracts data base. It was necessary to develop procedures for acquisition, extraction and transfer of the on-line/archive TSMO and GenCo data from the existing web-based system to the new trading support system. This paper describes both tasks.

\section{Old System}

Architecture of old (transitional) system made especially for PE EPS is shown on Figure 1. Two very important parts are DB Contracts and WEB Diary applications which are based on Contracts_EPS and db_diary_EPS [1].

DB Contracts is database driven PHP (4.3.9) application which allows contract data input as well as schedules, actual plant productions (hourly production of all power plants) and scheduled and actual active power interchanges, pump storage operation data, total production, total consumption, losses, etc. Those data originate from different sources:

- Real-time data obtained through SCADA (Supervisory Control and Data Acquisition system)

- Manual entry (including manual entry of missing real time data by plant operators)

- Other information systems within PE EMS (mainly for schedule data)

Some data are also result of calculations.

For hydro power plant values transferred are per plant and for thermal power plant values transferred are per 
unit.

Hydro power plants are treated as single units, and consequently all data for them are "per plant". In case of thermal power plants each unit is treated separately and consequently all data are "per generating unit".

As Contracts_EPS, db_diary_EPS is MySQL 5.0.26 database. It is not connected solely to trading, but it is also used for power plant operation monitoring.

\section{New system}

IPESOFT EDA (Energy Data Archive) is a tool used as data storage for processing timeline data which architecture is shown on Figure 2. Timeline consists of values collected, recorded or observed over a period of time, i.e. they are sorted chronologically from past to present data. This special data structure is used to store

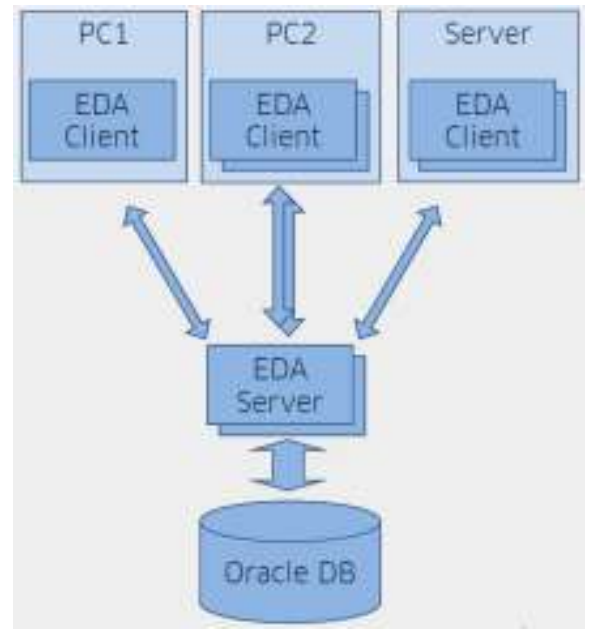

Figure 2 EDA architecture

values that change in time and it is based on DB Oracle $11 \mathrm{~g}$ Enterprise Edition.

Basic functions of IPESOFT EDA Data Storage are:

- To store, process and maintain large data volumes in the long-term (verified application performance with more than a million timelines)

- To provide support for collecting and processing data from other systems in the real time (online)

- To provide data export and import support (XML, XLS)

- Mathematical, statistical and analytical data operations

- To organize data into groups and scenarios

- To create user balances, statistics and reports

- To visualize data as tables and graphs

- To allow further data processing

IPESOFT EDA Data Storage can be used as a separate tool or module to collect, calculate and visualize data as in the IPESOFT REMS, IPESOFT SELT, IPESOFT SELT THERM systems.

IPESOFT EDA is used for collecting data required for functioning of the "Front Office".

\section{Our work}

Two tasks we had to do were:

- Migration/mapping (Contract_EPS to new system)

- Fetching other data important for electricity trading

Data about counterparties and addresses, contracts (referenced with traded volume and trade basis), products was planned for migration from Contract_EPS database. Data about delivery points, markets, trading books, and payments conditions was planned for manual input into new system.

Migration was made up of next steps:

1. Export from old system

2. Conversion to importable format (optionally)

3. Data completion with additional information

Export from old system to XLS file was made by our partners from PE EPS. Conversion was made according to mapping rules specified by partners from IPESOFT using MS Access as most reliable tool for work with such quantity of data in order not to make unnecessary mistakes and loss of data. During migration simple SQL scripts were used. Migration was done twice, first time in order to prepare test system and second time before start of implementation of the system.

Other data, important for electricity trading, was data about plant production (per plant, total, and total without Kosovo) and consumption (total and total without Kosovo). Logical source of data was SCADA system which collects power plants data. However, after analysis we concluded that SCADA system does not provide sufficient data for our needs, because significant amount of data is manually entered to db_diary_EPS. Because db_diary_EPS was only source with complete set of required input data we decided to use it as source of data for power plant production and consumption. Since the db_diary_EPS database has much more complex structure than SCADA archive database (which contains basically recorded measurement and statuses "time series") consequently conversion procedures required more complex but still feasible design.

In order to access data it was necessary to develop software for data extraction. We analyzed different combination of programming languages/operating 


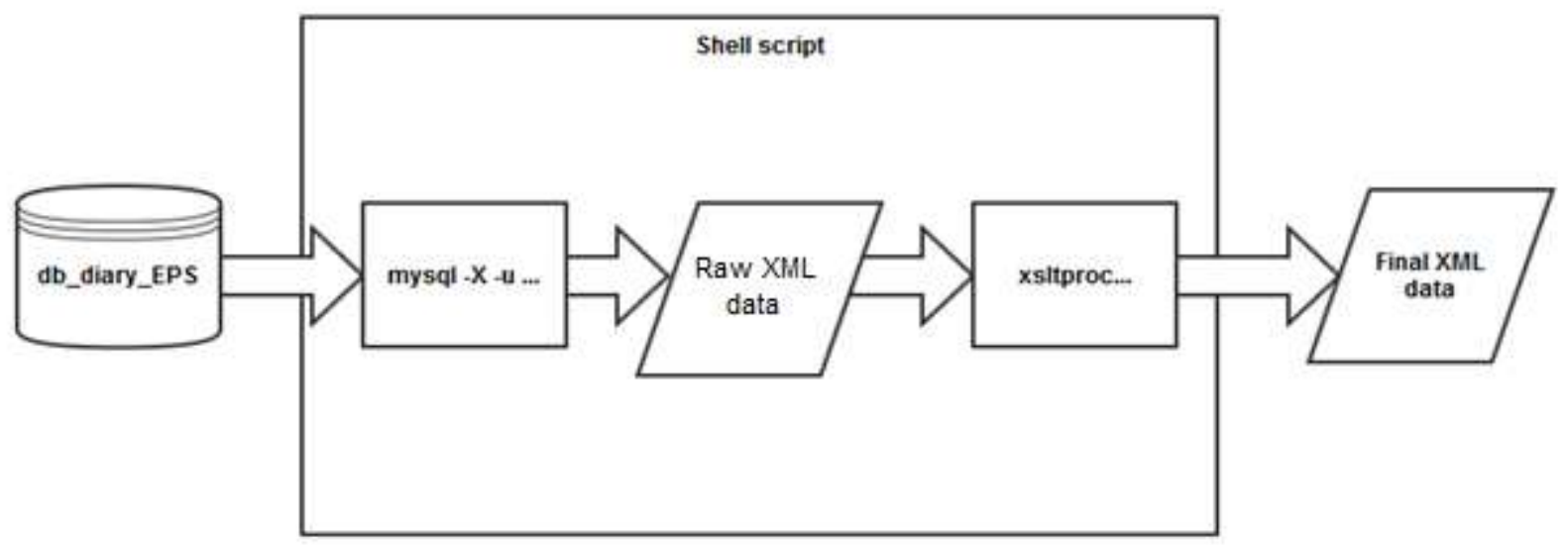

Figure 3. Very simplified extraction process block diagram

systems such as: C++/Unix, Visual Basic/Windows (which has rapid development cycle), and Java (as universal framework). db_diary_EPS is MySQL database on Linux, so we decided that we should use existing tools within MySQL distribution, libxml2 library and standard XSLT transformation in form of shell script. The solution based on shell scripting (Figure 3.) has one additional advantage which is that end user can adjust or modify shell script in order to accommodate possible changes in source database structure, system organization, or user requirements during software lifetime. The solution based on compiled application requires that software provider do all modification and maintenance of source code. The libxml2 is a software library for parsing XML documents. It was written in the $\mathrm{C}$ programming language, and originally developed for the GNOME project, but its tools like xsltproc (XSLT processor) can be used directly without compilation.. XSLT (Extensible Stylesheet Language Transformations) is a language for transforming XML documents into other XML documents, or other formats such as HTML, plain text or into XSL Formatting Objects, which may subsequently be converted to other formats, such as PDF PostScript and PNG. The original document is not changed; rather, a new document is created based on the content of an existing one.

Shell script that we developed provides opportunity for choice of date and/or directory in which data will be stored in form of XML file. Extraction is done by complex SQL query (default date is yesterday). After that row data is transformed into final XML file which structure is determined by IPESOFT. Shell script is automatically executed every night. Automation is conducted by cron - time-based job scheduler in UNIX- like operating systems. Cron is driven by crontab (cron table) configuration file that specifies shell commands to run periodically on a given schedule. Thus obtained file is then loaded into EDA

\section{Experience from initial practical use}

Almost all relevant data from the old system were extracted, transformed and loaded into new system database without need to perform manual corrections and interventions. This imported data are used as initial data set for the new system which is still being tuned and improved.

In January 2015, the ISSSE functionality package 1 was implemented.

The particular package is mostly related to the front office activities, such as management of electricity trade contracts (Figure 4.), management of business information regarding trading counterparties, support of trading products in various time horizons, import of market data from various market places (exchanges, OTCs, broker platforms), recording transmission capacities auctions, import of forward price curves, support of data exchange with TSO in standard ENTSO-E formats, etc.

The functionalities of the package 1 have been fully utilized by the front office of PE EPS

The implementation of the package 1 coincided with the start of operation of PE EPS's subsidiary on Hungarian Power Exchange (HUPX), and provided functionalities were necessary for successful operation of organized electricity market.

Moreover, EPS plans to become active on several other power exchanges in the region, which means that trading activities will become more complex, and the 
support of the sophisticated ETRM system will be of the selected and used also proved adequate and flexible. utmost importance.

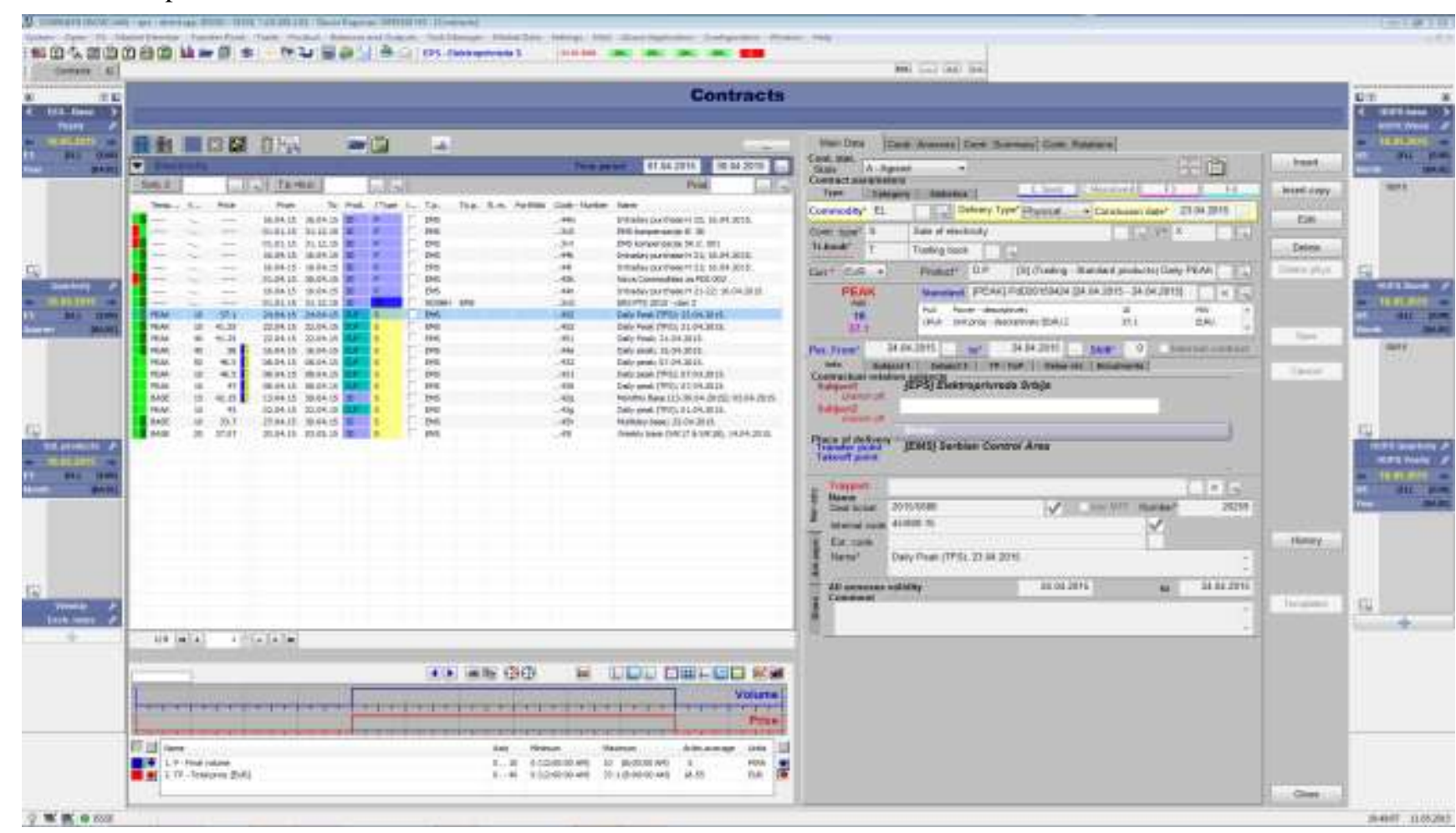

Figure 5 Contracts display - new system

At the end of April 2015, ISSSE functionality package 2 was implemented.

This functionality package, among other things, is related to physical positional analysis, financial position analysis, predefined structure for risk definition and risk management, Mark-To-Market analysis, monitoring of positions in real time, trading limits definition, provision of standard reports and analytical tools, and preparation of invoices.

The implementation of the rest of packages of ISSSE will be completed by the end of the year.

\section{Conclusion}

To enable a larger amount of trading at different markets and with different products, PE EPS have procured new state-of-the-art trading system of the ETRM type. To avoid unjustified costs of 1) massive data entry of data that are available in the legacy trading system and 2) daily manual entry of generation/consumption data from another existing IT system (Web Diary), specific migration tool and data integration software was developed and implemented. Initial experiences with both solutions described are fully satisfactory regarding data completeness, validity, and ease of use. Having in mind allowable resources and time allotted IT technologies

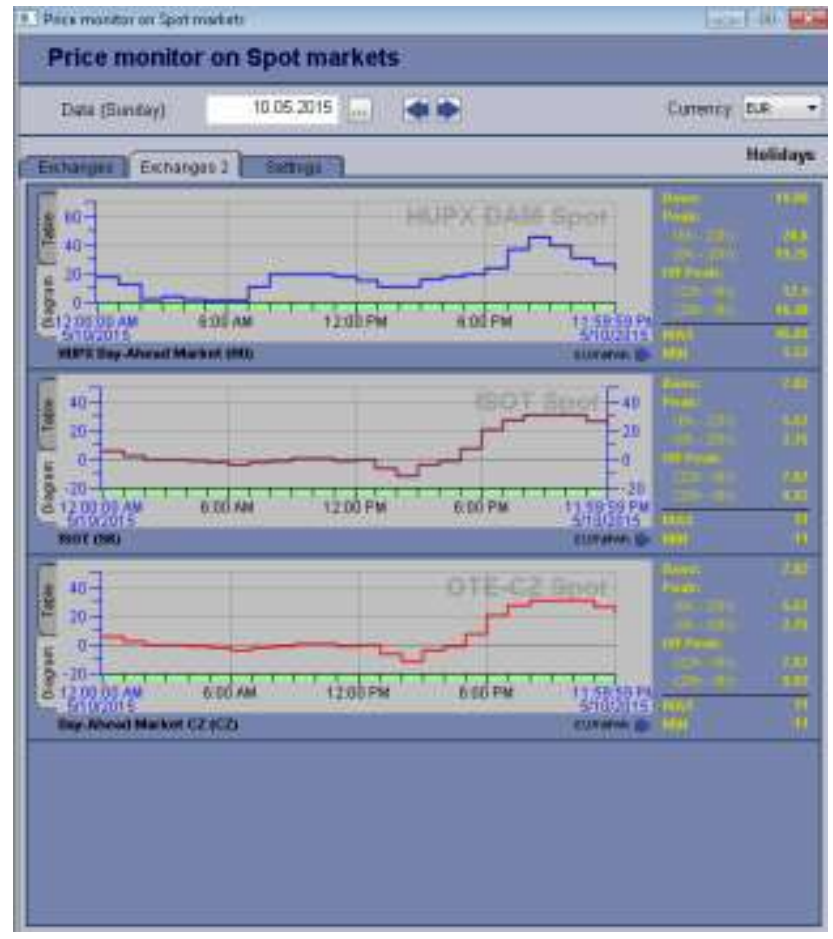

Figure 4 Price monitor display - new system 


\section{References}

[1] Radomir Stamatović, Svetlana Pandilović, Boris Jovanović, "Elektronski pogonski dnevnik webDiary" [Electronic dispatcher operating log webDiary], 15th Symposium Control and Telecommunications in Power System, Donji Milanovac, Serbia, 14-16th October 2012.

[2] R. Burk, D.B. Horvath, UNIX Unleashed: System Administrator's Edition Hardcover, Indianapolis, IN: SAMS Publishing, Oct 1997
[3] Radhakrishna, V.; SravanKiran, V.; Ravikiran, K., "Automating ETL process with scripting technology," Engineering (NUiCONE), 2012 Nirma University International Conference on , vol., no., pp.1,4, 6-8 Dec. 2012

[4] www.aers.rs

[5] www.eps.rs

[6] www.ipesoft.eu 